\title{
Correction to: Management of Blood Pressure after Acute Ischemic Stroke
}

\section{Zachary Bulwa ${ }^{1}$ - Camilo R. Gomez ${ }^{2}$. Sarkis Morales-Vidal ${ }^{3}$. José Biller ${ }^{3}$}

Published online: 25 May 2019

(C) Springer Science+Business Media, LLC, part of Springer Nature 2019

\section{Correction to: Curr NRNS Rep (2019) 19:29 https://doi.org/10.1007/s11910-019-0941-z}

The original version of this article unfortunately contained a mistake.

In page 29, the correct formula for cerebral perfusion pressure should be:

$\mathrm{CPP}=\mathrm{MABP}-\mathrm{ICP}$

The original article has been corrected.

Publisher's Note Springer Nature remains neutral with regard to jurisdictional claims in published maps and institutional affiliations.

The online version of the original article can be found at https://oi.org/ 10.1007/s11910-019-0941-z

\section{Camilo R. Gomez}

crgomez@missouri.edu

1 Department of Neurology, Pritzker School of Medicine, University of Chicago, Chicago, IL, USA

2 Department of Neurology, University of Missouri Columbia, Columbia, MO, USA

3 Department of Neurology, Stritch School of Medicine, Loyola University Chicago, Maywood, IL, USA 